\title{
Study on Analysis Model of Key Influencing Factors of Urban Environment Livability
}

\author{
Hong-xue XU \\ School of Information Engineering \\ Shenyang University \\ Shenyang, China \\ hongxuexu@163.com
}

\author{
Xiu-ying GUO* \\ School of Information Engineering \\ Shenyang University \\ Shenyang, China \\ 13889392901@163.com
}

\begin{abstract}
The livability of urban environment is affected by many factors, which play a major decisive role in the impact of factors known as the key influencing factors, such as greening rate, traffic convenience, residents' quality, medical technology and commercial service quality. Study the inherent changes of the key influencing factors of urban livability and its key influence on the livability of urban environment, based on the theory of system dynamics and the method of systematic analysis, the system dynamic model of each key influencing factor of urban environmental livability is constructed, and the consistency and validity of the model were tested by parameter estimation method. The establishment of system dynamics model of each key influencing factor of urban environment livability can help people to understand and master the influence degree of each key influencing factor on urban environment livability, in order to determine the urban livable environment simulation algorithm and the development of simulation systems well prepared.
\end{abstract}

Keywords-environment livability; influencing factors; system dynamics; system simulation

\section{INTRODUCTION}

Urban livable environment problem is a systematic problem which involves a wide range and complex relationship [1-2]. The livability of urban environment is affected by many factors, some of factors which affect the great quality of urban livable environment, we call those are key influencing factors.

The so-called key influencing factors are refer to the people recognized for play a crucial role in the quality of livable urban, once these key influencing factors can't reach a certain level, regardless of how to change other factors, the livable environmental quality can change very tiny.

The key influencing factors have great influence on the livable environment quality of the urban. Therefore, it is necessary to establish the key influencing factor analysis model and use the analysis model to analyze the key influencing factors.

The urban livable environmental system includes all the aspects factors of natural environment and social environment [3-5].

In this paper, some key influencing factors which have significant influence on urban livable environmental system are selected as the research object [6-10], including greening rate, the traffic convenience degree, residents' quality, the medical technology level, the residents' quality and the comercial service quality [11-14].

Based on the theory of system dynamics and the method of system analysis [15-17], the system dynamic model of key influencing factors of urban environment livability is constructed.

Combined with the valid data provided by the Statistical Yearbook of Tiexi District of Shenyang City [18], the consistency and validity of the model are tested by parameter estimation method. The test results prove the validity of the constructed model.

\section{THE KEY INFLUENCING FACTORS OF URBAN ENVIRONMENT LIVABILITY}

\section{A. Greening Rate}

Green construction is an important part of the livable urban construction [6].

Good green not only can purify the environment, reduce pollution, but also can provide a beautiful and comfortable environment for residents, so that the residents are more likely to get close to nature and enhance people's sense of happiness.

Greening rate is mainly determined by the actual green area and total land area, the total land area in a long period of time almost does not change, can be regarded as constant.

The actual green area is affected by the planned new green area and natural degraded green area, the planned new green area is expressed as the proportion of planned new green area and the area of natural degraded green area is expressed as the proportion of natural degraded green area.

Taking into account the difficulty in data acquisition and the representation of key factors when analyzing problems, only the proportion of new public green area, the proportion of new production green area and the proportion of new dedicated green area will be selected in this paper to constitute the proportion of green area planned to be added.

\section{B. Traffic Convenience Degree}

With the gradual improvement of the residents' life quality and the increase of entertainment, people travel is also rising, the residents' requirements of the transport is also more and more strong [7]. 
Bus sharing rate, taxi sharing rate and car sharing rate all have a certain influence on the traffic convenience degree.

The bus sharing rate, car sharing rate and taxi sharing rate is affected by the total population and the number of bus, car and taxi.

The travel amount of population is determined by the number of trips per capita and the total population, and the travel amount of bus, car and taxi is determined by the total amount and travel frequency of bus, car and taxi.

The total population amount is the difference between the birth and death population, birth and death population is determined by birth and death rates, respectively.

\section{Residents' Quality Level}

The level of education will affect the quality level of the residents [8].

The employed numbers of primary education, secondary education and higher education all have an impact on the quality level of residents.

The employed numbers of different levels are affected by the number of graduates and the employment rate.

The employment rate is a variable over time, and the graduates of different levels are determined by the corresponding graduation rate and the number of students, the number of students is affected by enrollment rate and graduation rate.

\section{Medical Technology Level}

Medical technology level is an important indicator for medical treatment the residents need to refer to [9].

The medical technology level is affected by the hospital fixed assets, proportion of high-tech talent and hospital number. The hospital fixed assets is the difference between the increment of hospital fixed assets and the depreciation of hospital fixed assets.

There is a certain relationship between the proportion of high-tech talent and the hospital total income, the hospital total income earned by the government investment and the hospital business income.

The hospital business income is divided into hospital outpatient profit and hospital profit, and the hospital total incomes also have an impact on hospital fixed assets. The hospital number can be treated as constant.

\section{E. Commercial Service Quality}

With the improvement of people's living standard, the demand of business has not only remained in the product quality, but pays more attention to the commercial service quality, therefore the commercial service quality level also has certain influence on livable environment [10].

Commercial service quality affects unreasonable proportion of commodity prices, the proportion of high-quality staff and convenient facilities investment proportion.

Unreasonable proportion of commodity prices is determined by the standard average prices of commodity and average price of commodity, the average price of commodity affected the total price of the commodity and the total number of commodity.
There is a certain relationship between the proportion of high-quality staff and commercial total income, commercial total income is composed of commercial profit and commercial loss, convenient facilities investment proportion is decided by the commercial investment and government investment, and there is a certain relationship between comercial investment and commercial income.

\section{THE ANALYSIS MODEL OF URBAN ENVIRONMENT LIVABILITY KEY INFLUENCING FACTORS}

\section{A. Greening Rate Analysis Model}

The greening rate analysis model is shown in Figure 1.

The mathematical expressions of greening rate model are: $\mathrm{Z}=\mathrm{INTEG}(\mathrm{Z} 1-\mathrm{T}, \mathrm{C}) ; \mathrm{Z} 1=\mathrm{Z} * \mathrm{~B} ; \mathrm{B}=\mathrm{B} 1+\mathrm{B} 2+\mathrm{B} 3$; $\mathrm{T}=\mathrm{Z} * \mathrm{~T} 1 ; \mathrm{B} 1=$ A FUNCTION OF(Time); B2=A FUNCTION OF(Time); B3=A FUNCTION OF(Time); $\mathrm{L}=\mathrm{S} /\left(\mathrm{S} 1{ }^{*} \mathrm{G}\right)$; $\mathrm{S} 1=\mathrm{B}-\mathrm{T} 1 ; \mathrm{S}=$ Z1-T; T1=A FUNCTION OF(Time); $\mathrm{C}=\mathrm{C} 1$ (C1as constant ); $\mathrm{G}=\mathrm{C} 2$ (C2 as constant).

$\mathrm{Z}$ represents total green area, Z1 represents green area plans to add, $\mathrm{T}$ represents degraded area, $\mathrm{C}$ represents the initialization of the total green area, B represents proportion of green area plans to add, B1 represents proportion of public green area plan to add, B2 represents proportion of units green area plan to add, B3 represents proportion of production green area plan to add, T1 represents proportion of degradation, $\mathrm{L}$ represents green rate, $\mathrm{S}$ represents the green area actual to add, S1 represents proportion of green area actual to add, $\mathrm{G}$ represents total area.

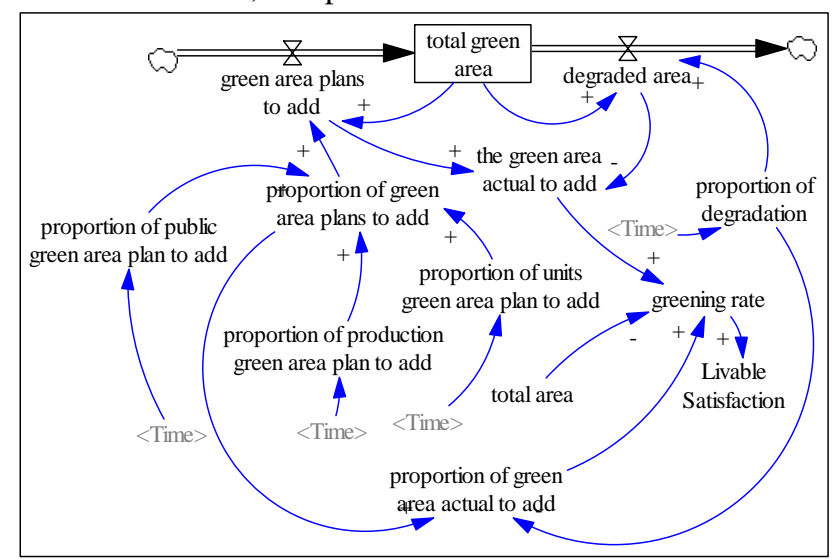

Figure 1. Greening rate analysis mode

\section{B. Traffic Convenience Degree Analysis Model}

The traffic convenience degree analysis model is shown in Figure 2.

The mathematical expressions of traffic convenience degree model are: T=INTEG(Tr-Ts,T0); Tr=T*Trv; Trv=A FUNCTION OF(Time); Tsv=A FUNCTION OF(Time); Ts= T*Tsv; Tz=T*Tp; Tp=A FUNCTION OF(Time); Tbv= $\mathrm{Tb} / \mathrm{Tz} ; \mathrm{Tb}=\mathrm{Tbf}+\mathrm{Tbm}$; Tbm=A FUNCTION OF(Time); Tcv= Tc/Tz; Tc=Tcf*Tcm; Tcf=A FUNCTION OF(Time); Tcm= A FUnCTION OF(Time); $\mathrm{Ttv}=\mathrm{Tt} / \mathrm{Tz} ; \mathrm{Tt}=\mathrm{Ttf} * \mathrm{Ttm} ; \mathrm{Ttf}=\mathrm{A}$ 
FUNCTION OF(Time); Ttm=A FUNCTION OF(Time); $\mathrm{Tc}=\mathrm{Tbv}+\mathrm{Ttv}+\mathrm{Tcv} ; \mathrm{T} 0=\mathrm{C} 1(\mathrm{C} 1$ as constant $)$.

$\mathrm{T}$ represents total population, Tr represents birth population, Ts represents death population, T0 represents initialization of total population, Trv represents birth rate, Tsv represents death rate, Tp represents the number of per capita trip times, Tbv represents bus sharing rate, $\mathrm{Tz}$ represents travel amount, Tb represents bus trips, Tbf represents bus trips frequency, Tbm represents bus number, Tcv represents car sharing rate, Tc represents car trips, Tcf represents car trips frequency, Tcm represents car number, Ttv represents taxi sharing rate, $\mathrm{Tt}$ represents taxi trips, $\mathrm{Ttf}$ represents taxi trips frequency, Ttm represents taxi number, Tc represents Traffic convenience degree.

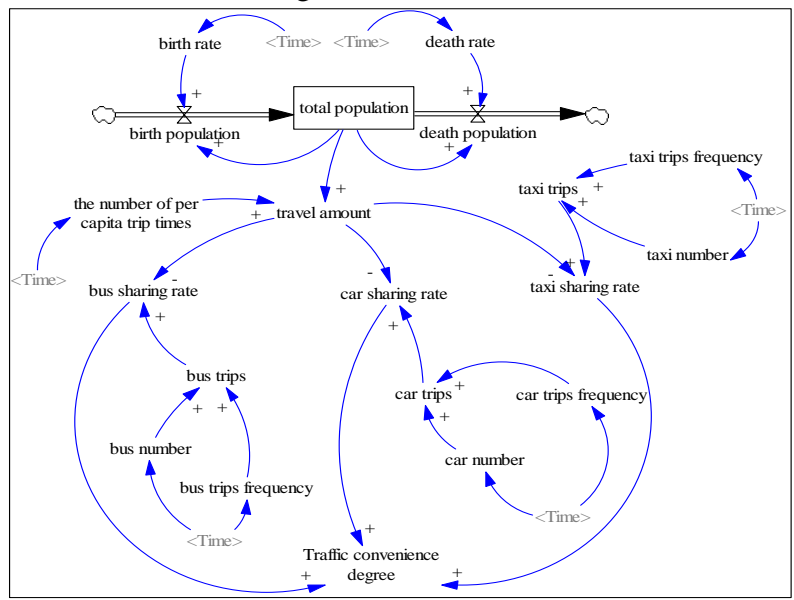

Figure 2. Traffic convenience degree analysis model

\section{Residents' Quality Level Analysis Model}

The residents' quality level analysis model is shown in Figure 3.

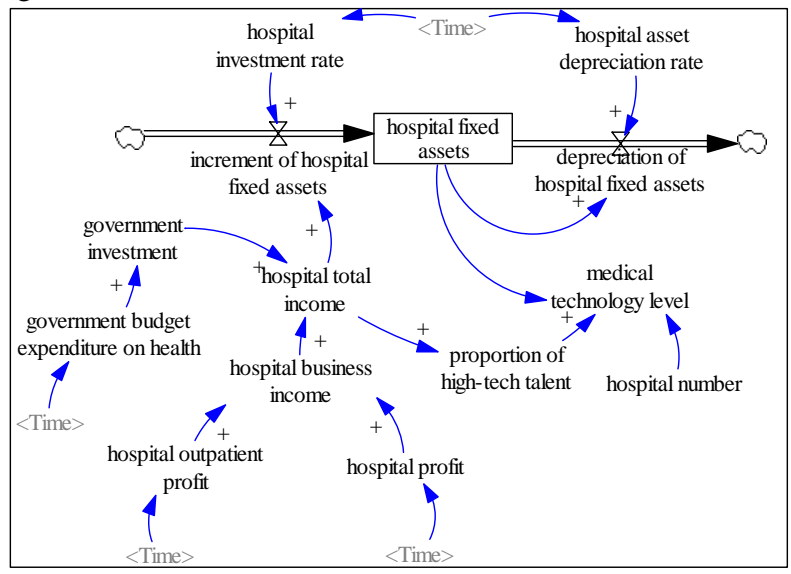

Figure 3. Medical technology level analysis model

The mathematical expressions of residents' quality level model are: $\mathrm{P}=$ INTEG(Pr-Pb,P1); $\mathrm{Pr}=\mathrm{Pv} * \mathrm{Px} ; \mathrm{Px}=\mathrm{A}$ FUNCTION OF(Time); Pv = A FUNCTION OF(Time); $\mathrm{Pb}=$ A FUNCTION OF(P); $\mathrm{Pbs}=\mathrm{Pb} ; \mathrm{Pjv}=\mathrm{A}$ FUNCTION OF(Time); Pj = Pjv*Pbs; Ps =1-Pjv; M=INTGE(Mr-Mb,M1);
Mr=Pbs*Ps; Mb=A FUNCTION OF(M); Mbs=Mb; Mjv=A FUNCTION OF(Time); $\mathrm{Mj}=$ Mjv*Mbs; $\mathrm{Ms}=1-\mathrm{Mjv}$; $\mathrm{P} 1=\mathrm{C} 1$ (C1 as constant); G=INTEG(Gr-Gb,G1); Gr=Mbs*Ms; $\mathrm{M} 1=\mathrm{C} 2$ (C2 as constant); $\mathrm{Gb}=\mathrm{A}$ FUNCTION OF(G); Gjv=A FUNCTION OF(Time); Gbs=Gb; $\mathrm{G} 1=\mathrm{C} 3(\mathrm{C} 3$ as constant); $\mathrm{Gj}=\mathrm{Gj} v^{*} \mathrm{Gbs}$; $\mathrm{U}=\mathrm{A}$ FUNCTION OF(Pj+Mj+Gj).

$\mathrm{P}$ represents primary represents education number in school, Pr represents primary education enrollment rate, $\mathrm{Pb}$ represents primary education graduation rate, $\mathrm{P} 1$ represents initialization of primary education number in school, $\mathrm{Pv}$ represents primary education enrollment ratio, Px represents school-age population, Pbs represents primary education graduation numbers, $\mathrm{Pj}$ represents employment in primary education, Pjv represents primary education employment rate, Ps represents primary education enrollment ratio, $\mathrm{M}$ represents secondary education number in school, Mr represents secondary education enrollment rate, Mb represents secondary education graduation rate, M1 represents initialization of secondary education number in school, Mbs represents secondary education graduation numbers, Mjv represents employment rate employment rate, $\mathrm{Mj}$ represents employment in secondary education, Ms represents secondary education enrollment ratio, $G$ represents higher education number in school, Gr represents higher education enrollment rate, Gb represents higher education graduation rate, G1 represents initialization of higher education number in school, Gjv represents higher education employment rate, Gbs represents higher education graduation numbers, $\mathrm{Gj}$ represents employment in higher education, U represents residents' quality level.

\section{Medical Technology Level Analysis Model}

The medical technology level analysis model is shown in Figure 4.

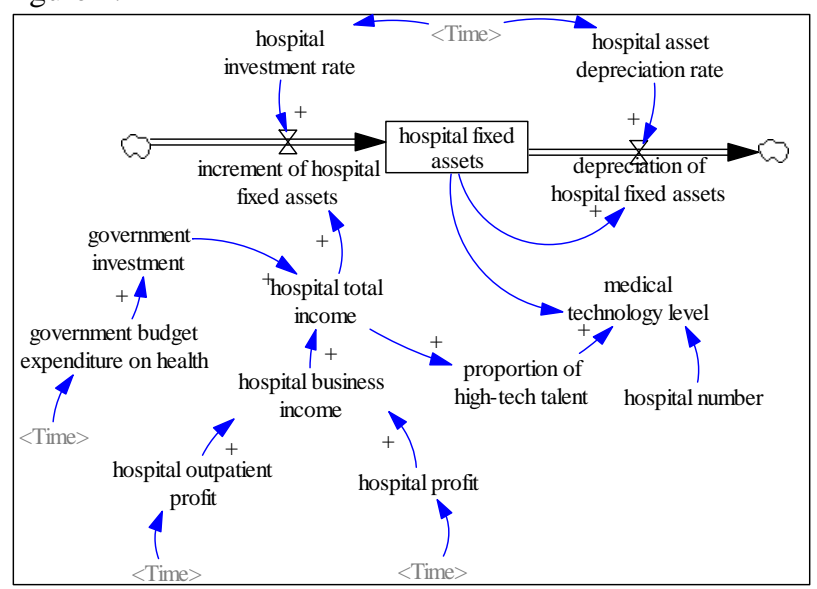

Figure 4. Medical technology level analysis model

The mathematical expressions of medical technology level model are: $\mathrm{H}=\mathrm{INTEG}(\mathrm{Hz}-\mathrm{Hj}, \mathrm{H1}) ; \mathrm{Ht}=\mathrm{A}$ FUNCTION OF(Time); Hv = A FUNCTION OF(Time); Hz = Hs*Ht; HS $=\mathrm{Hy}+\mathrm{Hr}$; $\mathrm{Hy}=\mathrm{Hzy}+\mathrm{Hmy}$; Hmy=A FUNCTION OF(Time); Hzy = A FUNCTION OF(Time); $\mathrm{Hj}=\mathrm{H}^{*} \mathrm{Hv} ; \mathrm{Hr}=\mathrm{A}$ FUNCTION OF(Hw); Hw = A FUNCTION OF(Time); Hg= 
A FUNCTION OF(Hs); He=A FUNCTION OF(H,H0,Hg); $\mathrm{H} 1=\mathrm{C} 1(\mathrm{C} 1$ as constant); $\mathrm{H} 0=\mathrm{C} 2(\mathrm{C} 2$ as constant $)$

$\mathrm{H}$ represents hospital fixed assets, $\mathrm{Hz}$ represents increment of hospital fixed assets, $\mathrm{Hj}$ represents depreciation of hospital fixed assets, $\mathrm{H} 1$ represents initialization of hospital fixed assets, Hv represents hospital asset depreciation rate, Ht represents hospital investment rate, Hs represents hospital total income, $\mathrm{Hr}$ represents government investment, Hy represents hospital business income, Hzy represents hospital profit, Hmy represents hospital outpatient profit, Hw represents government budget expenditure on health, $\mathrm{Hg}$ represents proportion of high-tech talent, He represents medical technology level, H0 represents hospital number.

\section{E. Commercial Service Quality Analysis Model}

The commercial service quality analysis model is shown in Figure 5.

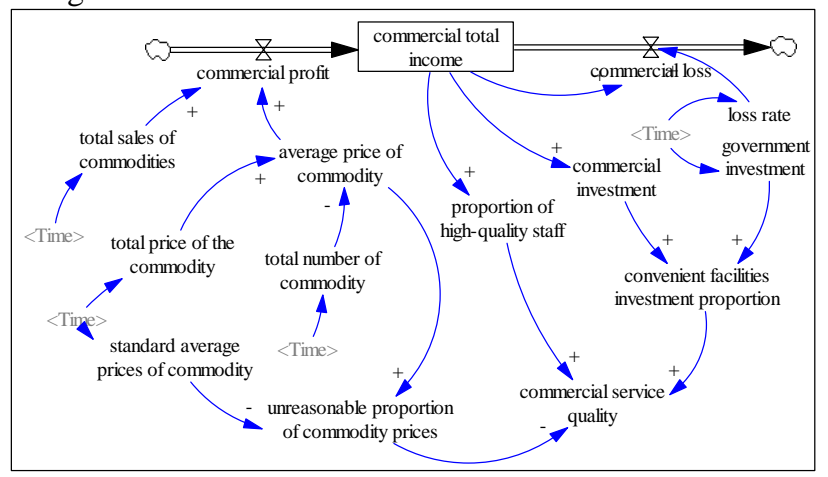

Figure 5. Commercial service quality analysis model

The mathematical expressions of commercial service quality model are: $\mathrm{Bz}=$ INTEG(B1-Be,B0); $\mathrm{B} 1=\mathrm{Bp} * \mathrm{Bx}$; $\mathrm{B} 0=\mathrm{C} 1(\mathrm{C} 1$ as constant); $\mathrm{Bx}=\mathrm{A}$ FUNCTION OF(Time); $\mathrm{Bp}=\mathrm{Bzp} / \mathrm{Bzm} ; \mathrm{Bpb}=\mathrm{C} 2(\mathrm{C} 2$ as constant $) ; \mathrm{Bzp}=\mathrm{A}$ FUNCTION OF(Time); Bzm = A FUNCTION OF(Time); $\mathrm{Be}=\mathrm{Bz} * \mathrm{Bev} ; \mathrm{Bn}=(\mathrm{Bp}-\mathrm{Bpb}) / \mathrm{Bpb} ; \mathrm{Bev}=\mathrm{A}$ FUNCTION OF(Time); $\mathrm{Br}=\mathrm{A}$ FUNCTION OF(Bz); $\mathrm{Bc}=\mathrm{A}$ FUNCTION $\mathrm{OF}(\mathrm{Br}, \mathrm{Bg}) ; \mathrm{Bg}=\mathrm{A}$ FUNCTION OF(Time); $\mathrm{Bb}=\mathrm{A}$ FUNCTION OF(Bc,Bs,Bn); Bs = A FUNCTION OF(Bz).

$\mathrm{Bz}$ represents commercial total income, B1 represents commercial profit, Be represents commercial loss, B0 represents initialization of commercial total income, Bp represents average price of commodity, $\mathrm{Bx}$ represents total sales of commodities, Bzp represents total price of the commodity, Bzm represents total number of commodity, Bev represents loss rate, $\mathrm{Br}$ represents commercial investment,
$\mathrm{Bc}$ represents convenient facilities investment proportion, Bg represents government investment, $\mathrm{Bn}$ represents unreasonable proportion of commodity prices, Bpb represents standard average prices of commodity, Bs represents proportion of high-quality staff, $\mathrm{Bb}$ represents commercial service quality.

\section{MODEL VALIDATIONS}

After the model is complete, the validity of the model must be tested to ensure the accuracy and reliability of the model, the test of model mainly includes consistency checking and model validation $[5,6]$.

Consistency checking includes the reasonable structure of the model, the dimensionless consistency, and appropriateness of the model boundaries and whether the model can reflect the real situation, detection of this part has been fully considered in the process of establishing and simulating the model, and we also carried on modification and improvement the disadvantage until it reaches the model consistency requirements.

Testing the validity of model mainly determine by the simulation of historical data, this model is not reliable if the simulation data and the historical data has a large disparity.

We use effective data provided by statistical yearbook of Shenyang city in Tiexi District [18] and the method of parameter estimation to assign parameter in the model, then according to the input data and the equation a group of results can be drawn.

The greening rate model is taken as an example, and the data of statistical yearbook of Shenyang city in Tiexi District is referenced. We use the 2010 data as initial data, and use real data and the estimated data to assign formula variables and equations of greening rate model. The results are shown in Table 1.

We can use the same method to assign formula variables and equations of traffic convenience degree model, residents' quality level model, medical technology level model and commercial service quality model, and the corresponding simulation results can be got. The fitting between the results of main variables and the actual data are shown in Table 2.

In the view of system dynamics, the error of simulation results within $10 \%$ is considered reasonable. As can be seen from Table 2, the simulated data errors are within the allowable error range, thus indicating the fit degree of simulated data and real data is better, so the model has certain credibility, the system can reflect the real situation.

\begin{tabular}{|l|l|}
\hline B1 & WITH LOOKUP(Time,([(2010,0.3)-(2014,0.6)],(2010,0.347),(2011, 0.398),(2012, 0.417),(2013, 0.436),(2014, 0.467))) \\
\hline B2 & WITH LOOKUP(Time,([(2010,0)-(2014,0.5)],(2010,0.065),(2011,0.154),(2012,0.263),(2013,0.357),(2014,0.454))) \\
\hline B3 & WITH LOOKUP(Time,([(2010,-0.2)-(2014,0)],(2010,-0.123),(2011,-0.031),(2012,-0.029),(2013,-0.013),(2014,-0.001))) \\
\hline T1 & WITH LOOKUP(Time,([(2010,0.02)-(2014,0.03)],(2010,0.029),(2011,0.026),(2012,0.024),(2013,0.022),(2014,0.023))) \\
\hline C & 6421492 \\
\hline G & 12476641 \\
\hline
\end{tabular}


TABLE II.

ERROR ANALYSIS OF SIMULATION RESULTS

\begin{tabular}{|c|c|c|c|c|c|c|}
\hline \multirow{2}{*}{ Project } & \multirow{2}{*}{ Type Value } & \multicolumn{5}{|c|}{ Particular year } \\
\hline & & 2010 & 2011 & 2012 & 2013 & 2014 \\
\hline \multirow{3}{*}{ Total green area (Square meter) } & Real value & 6421492 & 6601139 & 6973990 & 7167530 & 12476641 \\
\hline & Calculated value & 6421490 & 6194740 & 6954220 & 7144760 & 12416200 \\
\hline & Error value (\%) & 0.0000002 & 0.1 & 0.28 & 0.32 & 0.48 \\
\hline \multirow{3}{*}{ Travel amount (Million people) } & Real value & 137 & 151 & 166 & 181 & 197 \\
\hline & Calculated value & 132 & 147 & 159 & 172 & 192 \\
\hline & Error value (\%) & 3.64 & 2.65 & 4.21 & 4.97 & 2.54 \\
\hline \multirow{3}{*}{ High school (Person) } & Real value & 202308 & 214541 & 225398 & 386588 & 264048 \\
\hline & Calculated value & 202306 & 212502 & 223933 & 376420 & 260272 \\
\hline & Error value (\%) & 0.00005 & 0.95 & 0.65 & 2.63 & 1.43 \\
\hline \multirow{3}{*}{ Hospital fixed assets (Million Yuan) } & Real value & 2178 & 2316 & 2465 & 2679 & 2832 \\
\hline & Calculated value & 2173 & 2196 & 2309 & 2505 & 2631 \\
\hline & Error value (\%) & 0.0003 & 5.18 & 6.33 & 6.49 & 7.09 \\
\hline \multirow{3}{*}{ Commercial income (Million Yuan) } & Real value & 54450454 & 62624497 & 74150396 & 80146629 & 89444520 \\
\hline & Calculated value & 54450450 & 60833436 & 70665327 & 79305089 & 87092129 \\
\hline & Error value (\%) & 0.0000002 & 2.86 & 4.7 & 1.05 & 2.63 \\
\hline
\end{tabular}

\section{CONCLUSIONS}

Urban environmental is broad and complex relations system problems. It includes some key influencing factors which affect the great quality of urban livable environment.

In this paper, we based on the theory of system dynamics and using the method of system analysis, focus on the key influencing factors such as greening rate, traffic convenience degree, residents' quality level, medical technology level and commercial service quality to build system dynamics model, and the parameter estimation method is used to detect the consistency and validity of the model.

The model is also used to determine the simulation algorithms of urban environment livability and to develop the simulation system.

\section{ACKNOWLEDGMENT}

This work was financially supported by the science and enterprise competitive selection project of Shenyang City (Research on the risk management and remediation technology of urban ecological environment).

\section{REFERENCES}

[1] L.Y. Wu, "Introduction to science of human settlements," China Architecture \& Building Press, 2001, pp. 1-5.

[2] Q. Yu and J.T. Wang, "Study of livable city Construction," Value Engineering, 2016, 35(17), pp. 1-4.

[3] L. Wang, "Study on livable city theory and its influence factors," Zhejiang University, 2007, pp. 20-25.
[4] L.S. Ling and X.Z. Wen, "Study on influencing factors of livable city on the basis of interpretive structural model-a case study of Xinyang," Value Engineering , 2014(4), pp. 16-18.

[5] D.D. Yang, "Measurement and evaluation of urban ecologi-cally livable development ability based on state space model," Tianjin University of Technology, 2014.

[6] L.P. and X.Y. Wu, "Research on the evaluation index system of livable city," Journal of the Party School of CPC Jinan Municipal Committee, 2007(1), pp.16-21.

[7] F.X. Hu and X.J. Hu, "Construction on evaluation index system of urban livability.,” Ecological Economy, 2014, vol. 30(8), pp. 42-44.

[8] C. Li, "Study on assessment China's urban human settle-ments," East China Normal University, 2015.

[9] Z.W. Jiang and J. Zang, "On evaluation indexes system of ecological cities,” Shanxi Architecture, 2016, vol. 42(13), pp. 245-246.

[10] S.Q. Zhao and C.X. Liu, "Review and reconstruction on metric system of livable cities,” Value Engineering, 2016 (21), pp. 14-17.

[11] S.X. Lu and Q. Z. Qin, "Research on livable city theory,” Journal of Beijing City University, 2012(1), pp. 13-14.

[12] C.M. Fang, "Based on the compact Shenyang city develop-ment Research,” Shenyang Jianzhu University, 2012.

[13] W.Z Zhang, "The core framework of the livable city construction," Geographical Research, 2016, vol. 35(2), pp. 205-213.

[14] J. Zhao, "Analysis problems and respones in urban planning and construction,” Value Engineering, 2014(4), pp. 102-103.

[15] Q.F. Wang, "System dynamics,” Shanghai University of Finance and Economics Press, 2009, vol. 7, pp. 100-120.

[16] Q.F. Wang, "The complex system modeling theory, method and technology,” Science Press, 2011, vol. 4, pp. 110-160.

[17] F. Wu, "Research on TOD urban space design strategy on the basis of sustainable and livable urban development," Zhejiang University, 2014.

[18] Statistical Bureau of Shenyang District of Tiexi. Tiexi statistical yearbook, 2010-2014. 